\title{
The effect of CuSn intermetallics on the interstrand contact resistance in superconducting cables for the large hadron collider
}

\author{
C. Scheuerlein ${ }^{a)}$ \\ European Organization for Nuclear Research (CERN), CH-1211, Geneva 23, Switzerland \\ Ph. Gasser and P. Jacob \\ Eidgenössische Materialpriffungs- und ForschungsAnstalt (EMPA), CH-8600 Ditbendorf, Switzerland \\ D. Leroy, L. Oberli, and M. Taborelli \\ European Organization for Nuclear Research (CERN), CH-1211, Geneva 23, Switzerland \\ (Received 28 June 2004; accepted 24 November 2004; published online 11 January 2005)
}

The large hadron collider superconducting cables are submitted to a $200^{\circ} \mathrm{C}$ heat treatment in air in order to increase the resistance between the crossing strands $\left(R_{C}\right)$ within the cable. During this treatment the as-applied $\mathrm{Sn}-\mathrm{Ag}$ alloy strand coating is transformed into a $\mathrm{CuSn}$ intermetallic compound layer. The microstructure, the surface topography, and the surface chemistry of the nonreacted and reacted contings have been characterized by different techniques, notably focused ion beam, transmission electron microscopy, energy dispersive $x$-ray spectroscopy, and $x$-ray photoelectron spectroscopy. Based on the results obtained by these techniques the different influences that the intermetallics have on $R_{C}$ are discussed. The desired $R_{C}$ is obtained only when a continuous $\mathrm{Cu}_{3} \mathrm{Sn}$ layer is formed, i.e., a sufficient wetting of the $\mathrm{Cu}$ substrate by the tinning alloy is crucial. Among other effects the formation of the comparatively hard intermetallics roughens the surface and, thus, reduces the true contact area and it strongly affects the oxide growth on the strand surface. The oxide formed on the fully reacted coatings, which may essentially contain $\mathrm{Cu}$ oxides, appears to be more stable, both mechanically and thermally, as compared to the oxide formed on the tinning alloy. (C) 2005 American Institute of Physics. [DOI: 10.1063/1.1849429]

\section{INTRODUCTION}

For the construction of the superconducting (SC) magnets of the large hadron collider (LHC), ${ }^{1}$ CERN's next particle collider, about $7000 \mathrm{~km}$ of Rutherford superconducting cables, composed of either 28 or 36 strands, are needed. ${ }^{2}$

In order to reduce coupling currents between the strands and at the same time allow sufficient current sharing for the superconductor stability, the contact resistance of the crossing strands in the cables (interstrand contact resistance $R_{C}$ ) in the LHC magnets at $1.9 \mathrm{~K}$ should be between 20 and $100 \mu \Omega$. For this purpose a $\mathrm{Sn}-\mathrm{Ag}$ coating is applied onto the copper matrix of the strands, which is subsequently submitted to a $200^{\circ} \mathrm{C}$ heat treatment in air, lasting typically a few hours. The $\mathrm{Sn}-\mathrm{Ag}$ coating is applied by a continuous hot-dip process. ${ }^{3-5}$

The desired resistance between the crossing strands is obtained only after the cable heat treatment, which causes, among other effects, the interdiffusion of $\mathrm{Sn}$ and $\mathrm{Cu}$ and the formation of intermetallic phases, the modification and part removal of surface contaminants, and the growth of the surface oxides. Several researchers have studied the interstrand contact resistance in cables with different strand surfaces ${ }^{6,7}$ and the contact resistance of heat-treated Sn-Ag coatings, in particular. ${ }^{8}$ For most heat-treated strand types it is concluded that it is the surface oxide that determines $R_{C}$.

Since the development of the LHC strand coating, the

\footnotetext{
"Author to whom correspondence should be addressed; electronic mail: christian,scheuerlein@sern,ch
}

intermetallics in $\mathrm{Cu}-\mathrm{Sn}$ interdiffusion pairs have attracted much attention, in view of the development of lead-free solders ${ }^{9}$ and advanced joining techniques for electronic packaging and microelectronics applications (see, for instance, Ref, 10). In solder joints an intermetallic layer is generally present between the solder and the metal to be soldered, forming the required structural bond between both materials. " During prolonged storage or during heat treatments (solder reflow) the intermetallics grow, which is detrimental to the joint since intermetallics can reduce the wettability of pretinned substrates ${ }^{12}$ and they can degrade the mechanical properties of the joint. ${ }^{13}$

When $\mathrm{Sn}$ containing solders are used in combination with $\mathrm{Cu}$ the intermetallic compounds that are formed are $\mathrm{Cu}_{6} \mathrm{Sn}_{5}$ ( $\eta$ phase) and $\mathrm{Cu}_{3} \mathrm{Sn}$ ( $\varepsilon$ phase). ${ }^{14}$ The compound that is initially formed during the liquid-solid reactions is $\mathrm{Cu}_{6} \mathrm{Sn}_{5}$, which grows initially much faster than $\mathrm{Cu}_{3} \mathrm{Sn}$. Once all $\mathrm{Sn}$ is changed into $\mathrm{Cu}_{6} \mathrm{Sn}_{5}$ the $\mathrm{Cu}_{3} \mathrm{Sn}$ phase continues to grow at the expense of $\mathrm{Cu}_{6} \mathrm{Sn}_{5}$, forming small grain-sized planar layer's. A commonly used lead-free solder is the cutectic Sn$3.5 \mathrm{Ag}$ alloy, For $\mathrm{Sn}-3.5 \mathrm{Ag} / \mathrm{Cu}$ couples at $170^{\circ} \mathrm{C}$ and at $205^{\circ} \mathrm{C}$ a $t^{0.42}$ time dependence has been found for the $\mathrm{Cl}_{3} \mathrm{Sn}$ growth. ${ }^{15}$ The kinetics for the intermetallic formation and the intermetallic microstructure depend, for instance, on the cooling rate ${ }^{16}$ and the presence of other elements in the coating bath, suclı as $\mathrm{Cu}_{1}{ }^{17}$ which is dissolved in the coating bath from the strand during the coating process

In the $\mathrm{Sn}-3.5 \mathrm{Ag}$ solder $\mathrm{Ag}$ is present in the form of $\mathrm{Ag}_{3} \mathrm{Sn}$ particles, which are more or less finely dispersed, depending on the cooling rate. The presence of the $\mathrm{Ag}_{3} \mathrm{Sn}$ 
TABLE I. Melting point, mechanical properties, and electrical resistivity (at room temperature) of the strand coating materials found in literature.

\begin{tabular}{lcccc}
\hline \hline & $\begin{array}{c}\text { Melting point } \\
\left({ }^{\circ} \mathrm{C}\right)(\text { Ref. 14) }\end{array}$ & Hardness & $\begin{array}{c}\text { Young's modulus } \\
(\mathrm{GPa})(\text { Ref. 28) }\end{array}$ & $\begin{array}{c}\text { Electrical resistivity } \\
(\mu \Omega \mathrm{cm})\end{array}$ \\
\hline $\mathrm{Cu}$ & 1080 & $\mathrm{HV}_{0.5}=60-80^{\mathrm{a}}$ & 116.5 & 1.7 (Ref. 29) \\
$\mathrm{Sn}$ & 232 & & 46.9 & 11.5 \\
$\mathrm{Sn}-3.5 \mathrm{Ag}$ & 220 & $0.23 \mathrm{GPa}^{\mathrm{b}}$ (Ref. 30) & 51.3 & 12.3 (Ref. 9) \\
$\mathrm{Cu} 3 \mathrm{Sn}$ & 676 & $6.2 \mathrm{GPa}^{\mathrm{a}}$ (Ref. 31) & 134.2 & 8.8 (Ref. 32) \\
$\mathrm{Cu}_{6} \mathrm{Sn} \mathrm{n}_{5}$ & 415 & $6.5 \mathrm{GPa}^{\mathrm{c}}$ (Ref. 31) & 112.3 & 17.5 (Ref. 32) \\
$\mathrm{Ag}_{3} \mathrm{Sn}$ & 480 & $2.9 \mathrm{GPa}^{0}$ (Ref. 31) & 78.9 & \\
\hline \hline
\end{tabular}

${ }^{a}$ The copper hardness has been measured in the strand copper matrix of metallographically prepared strand cross sections before and after $200^{\circ} \mathrm{C}$ heat treatment, with the lower hardness values observed after heat treatment. ${ }^{\mathrm{b}} \mathrm{T}$ The hardness for the eutectoid $\mathrm{Sn}-3.5 \mathrm{Ag}$ (wt \%) alloy has been determined in a solder joint by nanoindentation using a Berkovitch indenter and an indent depth in the order of $100 \mathrm{~nm}$.

${ }^{\circ} \mathrm{For} \mathrm{Cu}_{3} \mathrm{Sn}, \mathrm{Cu}_{6} \mathrm{Sn}_{5}$, and $\mathrm{Ag}_{3} \mathrm{Sn}$ the hardness was measured on bulk samples with a Vickers indenter and a load of $10 \mathrm{~N}$.

particles slightly increases the solder strength as compared to pure Sn and they may prevent the formation of Sn whiskers as it is observed on thin Sn films on Cu substrates. ${ }^{18}$ At temperatures below $170^{\circ} \mathrm{C}$ the $\mathrm{Ag}$ content reduces the growth of CuSn intermetallics as compared to the intermetallics growth in interdiffusion couples of pure $\mathrm{Sn}$ and $\mathrm{Cu}$, while a similar growth rate is reported at $205^{\circ} \mathrm{C} .{ }^{15}$ As in the case of the pure $\mathrm{Cu}$ matrix, $\mathrm{Ag}$ is not dissolved in the $\mathrm{CuSn}$ intermetallic layer but it can be incorporated in the form of $\mathrm{Ag}_{3} \mathrm{Sn}$.

Like ceramics the covalently bonded interinetallic compounds are hard and brittle. Unlike ceramics and similarly to metals, intermetallics conduct electricity and heat rather well. In Table I some material properties found in literature for $\mathrm{Cu}_{3} \mathrm{Sn}$ and $\mathrm{Cu}_{6} \mathrm{Sn}_{5}$ bulk are compared with those for $\mathrm{Cu}$, Str, and the entectic Sn-3.5Ag (wt. \%) alloy. Despite the fact that the hardness values shown are difficult to compare because of the different measurement methods and parameters used, it is clear that the intermetallics are significantly harder than $\mathrm{Cu}, \mathrm{Sn}$, and their alloys.

In the present article the influence of the CuSn intermetallics on the contact resistance in LHC superconducting cables is assessed on the basis of experimental results that have been obtained by focused ion beam (FIB) analysis, a technique that has now become accessible for the characterization of surface coatings and oxide layers. ${ }^{19}$ FIB was used in combination with a transmission electron microscope (TEM) and energy dispersive $x$-ray spectroscopy (EDS). The types of oxides present on the strand surface have been determined by x-ray photoelectron spectroscopy (XPS).

\section{EXPERIMENT}

\section{A. The strand samples}

The samples that have been analyzed are LHC superconducting strands taken from cables of different manufacturers. One strand coating was analyzed in the as-applied state, i.e., without subsequent heat treatment. All other samples followed a $200^{\circ} \mathrm{C}$ treatment in air as it is applied to the LHC cables in order to obtain the required $R_{C}$. Before materials characterization the cable samples were used for $R_{C}$ measurements. The samples that were analyzed by FIB are described in Table II. One sample (heat-treated 02B) exhibits a rather high contact resistance while the contact resistance of the three 02D samples is below the specified limits.

The average strand coating thickness given in Table II is calculated from the Sn coating mass, which is routinely determined by wet chemistry methods, notably amperostatic coulometry ${ }^{20}$ and atomic absorption spectroscopy. The average Ag content in the strand coating is typically about 3.3 at. $\%,{ }^{21}$ i.e., somewhat below the eutectic composition of the $\mathrm{Sn}-\mathrm{Ag}$ system, which is 3.8 at $\%(3.5 \mathrm{wt} \%) \mathrm{Ag}{ }^{14}$ and significantly below the nominal $\mathrm{Ag}$ content in the strand coating bath, which is 5.5 at $\% \mathrm{Ag}(5 \mathrm{wt} \%$ of $\mathrm{Ag}$ ). An analysis of the coating bath samples obtained from different strand manufacturers shows that the bath contains also typically between 1 and 4 at $\%$ of $\mathrm{Cu}$ in addition to Sn and Ag.

Optical metallograpliy on different strand samples shows that the coating thickness along the circumference of one strand may vary by more than one order of magnitude, with thickness values ranging from a tenth of a micron to several

TABLE II. Heat-trealment time at $200^{\circ} \mathrm{C}$ in air, interstrand contact resistance $R_{C}$ (nt LFC operating conditions), and avernge Sn coating thickness for all strands of the cables from which samples were malyzed by FIB.

\begin{tabular}{lccc}
\hline Cable type & $\begin{array}{c}\text { Hent-treatment time } \\
(\mathrm{h})\end{array}$ & $\begin{array}{c}R_{C} \\
(\mu \Omega)\end{array}$ & $\begin{array}{c}\text { Average pure Sn thickness of the cable } \\
(\mu \mathrm{min})\end{array}$ \\
\hline O2B non heat treated & 0 & Not measured & 0.31 \\
02B heat treated & 9.4 & 213 & 0.31 \\
02D-n (heat treated) & 3 & 10 & 0.21 \\
02D-b (heat treated) & 8 & 11 & 0.31 \\
02D-c (heat treated) & 12 & 12 & 0.28 \\
\hline
\end{tabular}




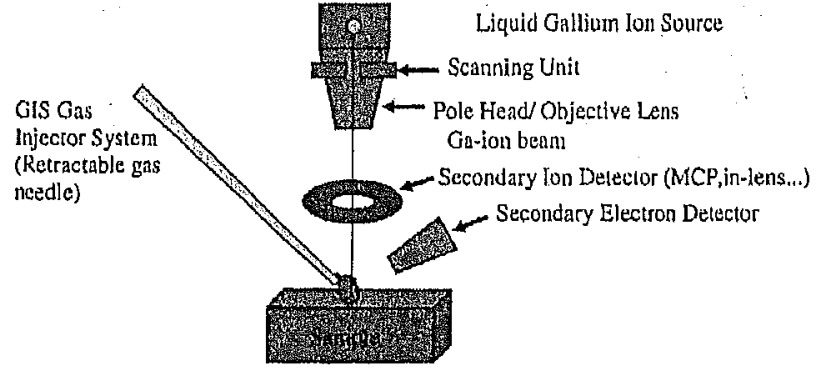

FIG, 1, Principal FIB setup as it was used for strand coating characterization.

microns. The important thickness variations that are observed by optical metallography have been confirmed by other methods, for instance, by x-ray fluorescence (XRF) thickness measurements. ${ }^{20}$ The coatings on heat-treated strands are found to be significantly thicker than the asapplied coatings. Since the densities of $\mathrm{Cu}_{6} \mathrm{Sn}_{5}$ and $\mathrm{Cu}_{3} \mathrm{Sn}$ are 8.28 and $8.90 \mathrm{~g} \mathrm{~cm}^{-3}, 32$ similar to the densities of $\mathrm{Cu}$ $\left(8.94 \mathrm{~g} \mathrm{~cm}^{-3}\right)$ and $\mathrm{Sn}\left(7.28 \mathrm{~g} \mathrm{~cm}^{-3}\right)$, one can expect an approximately fourfold thickness increase when the entire Sn transforms into $\mathrm{Cu}_{3} \mathrm{Sn}$.

\section{B. Focused ion beam}

FIB is a technique that allows a mechanically stress-free microcleaving by means of a gallium ion beam. The equipment setup is comparable to a scanning electron microscope, where the electron gun has been replaced or supplemented by a gallium ion beam (see Fig. 1). This technique has originally been developed for semiconductor device characterization and microstructure device modifications; by using additional process gases, botl material-selective milling and depositions of certain metals and oxides are possible too.

The ion beam allows both milling by ion sputtering and imaging by secondary electrons or secondary ions. The contrast signal, however, gives some more information than that of an electron microscope, since the penetration depth of the primary ions strongly depends on crystal orientation (ion channelling), so that grains become clearly visible. The cross sections shown in this article demonstrate this effect clearly, Neither previous chemical decoration or other pretreatment is necessary for this, nor any change to another instrument; the inspection can be performed directly in the tool, by just tilting the sample to $45^{\circ}$ to inspect the cross section.

The resolution of FIB is about $10 \mathrm{~nm}$. Even at Iow. current primary beam (less than $30 \mathrm{pA}$ ), slight sputtering of the material will take place. Normally, this is not critical; however, when preparing very thin TEM lamellas (less than $100 \mathrm{~nm}$ ) or surface imaging of ultrathin layers, the effect might not be negligible. Also, to cover those applications, many FIBs are equipped with an additional election-beam column (so-called "dual-beam" FIBs). This allows in situ scanning electron microscopy (SEM) inspections of the ion milling/polishing progress and final inspections of TEM lamellas. Since ion gun and electron gun are mechanically mounted at an angle of $42^{\circ}-52^{\circ}$, SEM inspection of the FIBmilled cross section does not need any tilting of the sample.
This is very advantageous in the case of precisely prepositioned samples.

\section{TEM sample preparation by focused ion-beam milling and TEM analysis}

When an extremely high resolution is needed, an investigation by means of transmission electron microscopy is necessary. This needs the preparation of a thin, electrontransparent film sample of less than 100-nm thickness. FIB is an ideal tool to perform such preparation. ${ }^{22}$ In principle, a cross section is made first from one side, followed by another cross section of exactly the same dimensions from the other side. The remaining thin TEM lamella can be cut out by FIB, too. Finally, the lamella is transferred by a glass needle to a TEM grid for further analysis. Samples for TEM investigation had been prepared with a FEI Strata DB 235 dual-beam (DB) FIB workstation. The DB workstation incorporates a FIB and a SEM column tilted with respect to each other by an angle of $52^{\circ}$.

The SEM column is equipped with a field emitter gun (FEG) emitter and an in-lens detector. The resolution is specified to be $3 \mathrm{~nm}$ at $1 \mathrm{kV}$. The FIB column is adjustable from $1 \mathrm{pA}$ to $20 \mathrm{nA}$ at $30 \mathrm{kV}$ with a specified resolution of 7 $\mathrm{nm}$, as given by the manufacturer. The instrument is equipped with four secondary electrons and ion detectors. The workstation has a digital patterning generator and four gas injection systems for deposition and specific etching processes.

The TEM specimens were prepared by milling an electron-transparent sample (e.g., $20 \mu \mathrm{m}$ long, $5 \mu \mathrm{m}$ wide, and $100 \mathrm{~nm}$ thick) out of a bulk metallographic sample. The TEM lamellas were transferred onto carbon-coated TEM grids (Ni) using an optical microscope and a micromanipulator.

TEM images and EDS analysis were performed on a $\mathrm{CM}$ 30 Philips with $\mathrm{LaB}_{6}$ source. The TEM was operated at 200 $\mathrm{kV}$. Images were recorded with a Gatan charge coupled device (CCD) model 694 in bright-field mode. The EDS analysis was performed with an energy dispersive $\mathrm{X}$-ray analysis (EDAX) DX-4 equipped with a Li-doped Si semiconductor detector, EDAX 139-10 with SUT window. For elemental analysis the TEM was operated in nanoprobe mode.

\section{RESULTS}

\section{A. Macroscopic appearance of the interstrand contact area in Rutherford-type LHC cables}

In Fig. 2 the strand deformation at the contact areas between the crossing strands inside the Rutherford-type cables can be seen. On a macroscopic scale it seems that the entire load bearing area has yielded plastically and is equal to the strand contact arca.

\section{B. FIB analysis of coating cross sections}

The coating microstructure and the coating surface topography have been examined by FIB. In Fig. 3 FIB cross sections through a nonheat-treated strand coating and its underlying copper matrix are shown. The FIB images reveal 


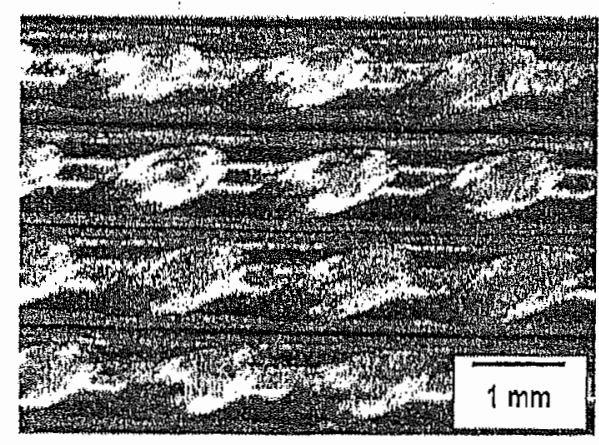

FIG. 2. Light microscope image of four strands inside a (non-heat-treated) Rutherford-type LHC cable. The interstrand contact areas are clearly visible. On a macroscopic scale the entire load bearing area seenns to be plastically deformed.

also the surface topography of the coating outside (left image) and inside the interstrand contact area (right image). The as-applied coating (left image) appears as clusters and not as a homogeneous film. During the cabling process the coating is smoothened inside the interstrand contact area (right image). The coating is too thin and irregular for a thickness measurement from the FIB images, The plastic strand deformation that occurs during cabling is also shown by grain size and shape variations that are caused by cold working of the $\mathrm{Cu}$ matrix.

The FIB inages shown in Fig. 4 have been acquired on a heat-treated strand from a cable for which comparatively high $R_{C}$ values have been measured (the strand was produced by the same manufacturer as the one shown in Fig. 3). The coating outside the contact zone (left image) is somewhat thicker than the adjacent coating inside the interstrand contact area. The rather rouglı surface topography appears to be similar in botll cases, i.e., contrary to what is observed on the nonheat-treated strand, inside the contact zone the coating is not smoother than it is outside the contact zone.

In Fig. 5 the FIB cross section of a strand coating that was reacted for $8 \mathrm{~h}$ (left image) is compared with that of a strand that was heated to $200^{\circ} \mathrm{C}$ for $3 \mathrm{~h}$ only. While after $8 \mathrm{~h}$ the coating is fully reacted, the upper part of the coating that

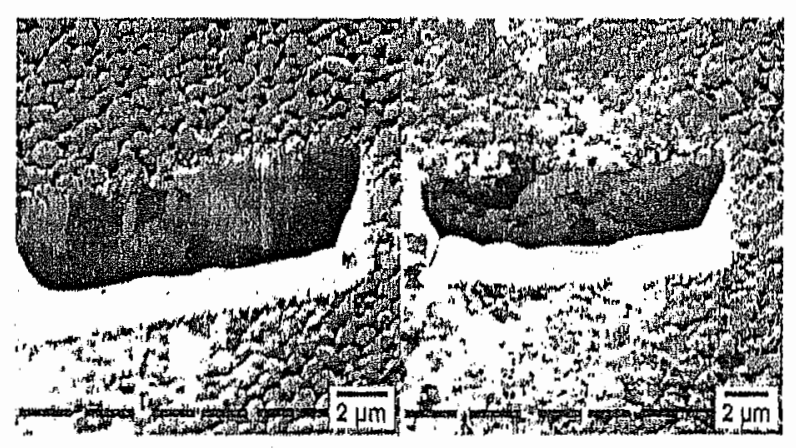

FIG. 3. FIB image of a conting cross section on a strand taken from nonheat-Irealed $02 \mathrm{~B} \mathrm{cable}$. The left image represents the $\mathrm{Sn}-\mathrm{Ag}$ coating outside and the right image inside the strand contact area. It can be seen that in the contact zone the coating surface yields plastically, thus increasing the true contact area. The strand deformation during cabling is also indicated by the $\mathrm{Cu}$ substrate grain size and shape changes that are revealed in the right FIB image.

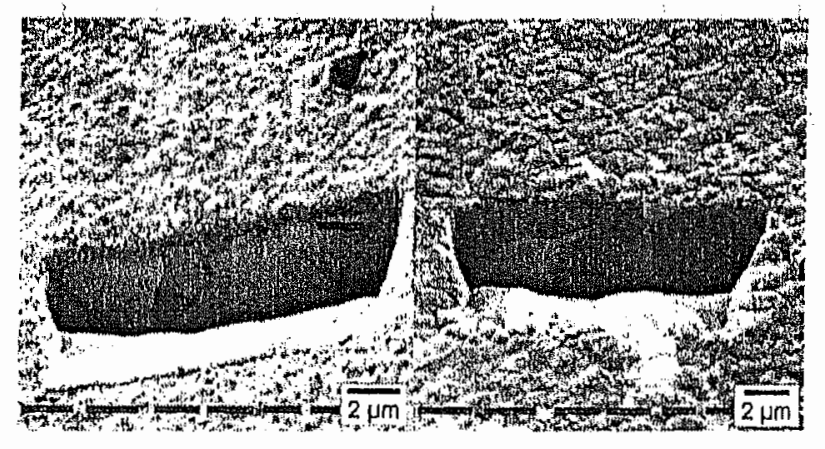

FIG. 4, FIB strand coating cross sections for strand taken from heat-treated 02B cable oulside (left image) and inside the interstrand contact area (right image). Both surfaces appear to be rougher than the as-applied coating.

was only heated during $3 \mathrm{~h}$ is not fully reacted. The surface of the fully reacted coating is much rougher than the surface of the coating which is only partly reacted.

Both FIB cuts in Fig. 5 have been obtained outside the contact area. As for all other strands that were examined the adjacent coating inside the compressed contact zone is sig. nificantly thinned.

\section{TEM analysis of the intermetallic layer and surface oxides}

Lamellas produced by FIB were analyzed in a TEM in order to examine the intermetallic layer in more detail and to estimate the thickness of the strand oxide after thermal treatment. In Fig. 6 the strand coating cross section obtained for the heat-treated cables 02B and 02D-b are shown.

On the $02 \mathrm{~B}$ sample a homogeneous small grain-sized intermetallic coating with a thickness between 0.7 and $1 \mu \mathrm{m}$ is seen, At the interface; so-called Kirkendall voids are visible, which are produced during the $\mathrm{Cu}$ and $\mathrm{Sn}$ interdiffision process. An EDS analysis at different points in the intermetallic layer gives a constant $S$ concentration across the layer: A precise quantitative result cannot be given because no standard sample was available but EDS indicates that the layer is composed of $\mathrm{Cu}_{3} \mathrm{Sn}$ rather than $\mathrm{Cu}_{6} \mathrm{Sn}_{5}$.

The FIB cross section of the 02D-b sample shows that on this sample the intermetallic layer is very irregular and even absent locally. Instead of the columnar grain shape on the 02B, sample grains appear to be rather round on the 02D

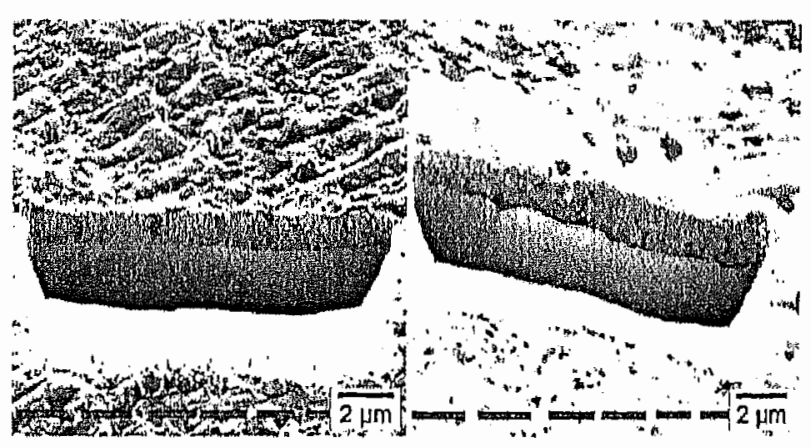

FIG. 5. Strand coating cross scctions produced by FIB for heat-trented strands taken from cable $02 \mathrm{D}-\mathrm{b}$ afler $8 \mathrm{~h}, 200^{\circ} \mathrm{C}$ (lef image) and $02 \mathrm{D}-\mathrm{a}$, after $3 \mathrm{~h}, 200^{\circ} \mathrm{C}$ (right image) outside the contact area. After $3 \mathrm{~h}, 200^{\circ} \mathrm{C}$ heat trealment the coating lins not entirely reacted and a smoolh alloy surfnce remains. 


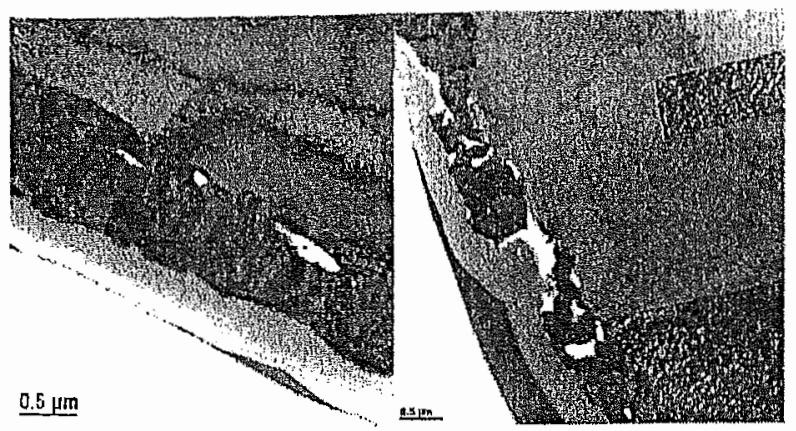

FIG, 6. TEM image of the CuSn intermetallic layer of strand taken from heat-treated $02 \mathrm{~B}$ cable (left image) and from 02D-b cable. On the 02B strand a homogenous $\mathrm{Cu}_{3} \mathrm{Sn}$ layer composed of small grains with a thickness of approximately 0.7 to $1 \mu \mathrm{m}$ is present. The bright areas at the CuSn intermetallic Cu interface are voids formed during the $\mathrm{Cu}-\mathrm{Sn}$ interdiffusion process. The intennetallic layer on the 02D-b strand is irregular and even locally entirely absent.

strands. The appearance of the other 02D samples $(02 \mathrm{D}-\mathrm{a}$ and $02 \mathrm{D}-\mathrm{c}$ ) is also similar to that of the 02D-b sample,

A TEM analysis of the FIB cross sections allows the oxide thickness on the outer strand surface to be estimated. In Fig. 7 the oxide layer on the $02 \mathrm{~B}$ and the 02D samples is shown. The oxide layer is embedded between the intermetallic layer and a protective Pt layer.
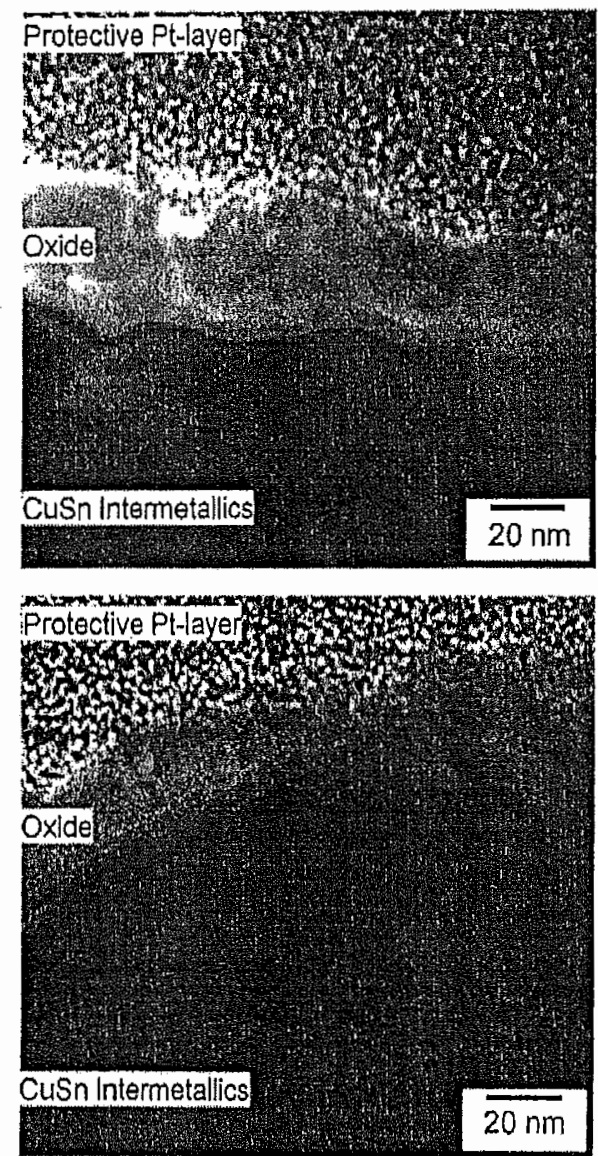

FIG. 7. TEM image of FIB cross seciion that shows the strand oxide layer on the $02 \mathrm{~B}$ (left image) and 02D-b sample (right image). On the $02 \mathrm{~B}$ strand a continuous oxide layer with a thickness of approximately $30 \mathrm{~nm}$ is found (the oxide is embedded between the intermetallic layer and the prolective Pt coating). The oxide layer on the $02 \mathrm{D}$ sample is irregular and locally its thickness is below the spatial resolution of the measurement method.
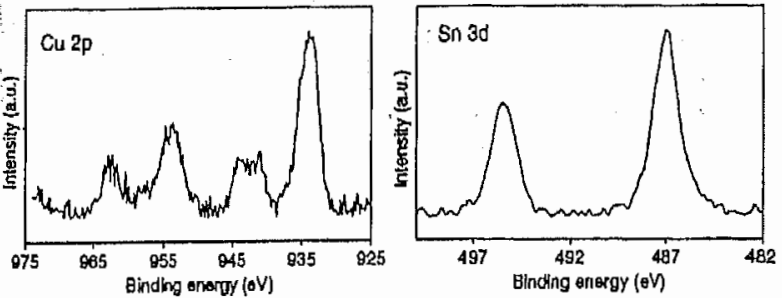

FIG. 8. High resolution spectra of the Cu $2 p$ and Sn $3 p$ photoelectron peaks acquired on the 02D-n sample. Peak slape and positions indicate that the surface oxides ate mainly $\mathrm{CuO}$ together with either $\mathrm{SnO}$ or $\mathrm{SnO}_{2}$ (these two Sn oxides are difficult to distinguish from the XPS data).

From Fig. 7 the oxide thickness that is present on the strand coating after the thermal treatment $\left(9.4 \mathrm{~h}\right.$ at $200^{\circ} \mathrm{C}$ in air) can be estimated as about $30 \mathrm{~nm}$. The oxide layers on all 02D strands that were examined are irregular with thicknesses on some locations not exceeding those of native oxides as they are formed at room temperature (about $3 \mathrm{~nm}$ ).

\section{Surface oxides as determined by XPS}

From the peak positions and shape in the high-resolution photoelectron spectra (see example in Fig. 8) it can be seen that the oxides on the outermost heat-treated strand surfaces contain $\mathrm{CuO}$ and either $\mathrm{SnO}$ or $\mathrm{SnO}_{2}\left(\mathrm{SnO}\right.$ and $\mathrm{SnO}_{2}$ cannot be easily distinguished by XPS).

The proportion of $\mathrm{Cu}$ and $\mathrm{Sn}$ oxides varies strongly for different strands within one cable and also for different cable types. For cables 02B and 02D-b the ratio $\mathrm{Cu}$ to $\mathrm{Sn}$ has been determined semiquantitatively for all strands (one analysis in the contact zone of each strand) and it was found that in average the $02 \mathrm{~B}$ strand surfaces are richer in $\mathrm{Cu}$ oxides than the $02 \mathrm{D}$ strands.

\section{DISCUSSION}

The bulk resistance of the $\mathrm{Cu}$ matrix in Cu-stabilized strands has a negligibly small influence on $R_{C}{ }^{8}$ Hence, the outer strand surface layer plays a dominant role on $R_{C}$. The coating cross-section images obtained by FIB and TEM show that during the $200^{\circ} \mathrm{C}$ cable heat treatment the asapplied coating is transformed into an intermetallic layer composed of small grains. EDS analysis indicates that when the entire $\mathrm{Sn}$ has reacted, mainly $\mathrm{Cu}_{3} \mathrm{Sn}$ is present in the coating, which is in agreement with the results presented, for instance, in Refs. 15 and 23.

The intermetallic layer may affect $R_{C}$ through its bulk resistivity, its surface topography, and through its influence on the surface oxides that are formed cluring the cable heat treatment in air. The contribution of each of these parameters on $R_{C}$ is discussed below.

\section{A. The influence of the intermetallic bulk resistivity and coating thickness on $R_{C}$}

It can be shown that for a certain cable type there is a trend of $R_{C}$ to decrease with increasing coating thickness under identical heat-treatment conditions. Therefore, heattreatment times are adapted, i.e., the thicker the average $\mathrm{Sn}-\mathrm{Ag}$ coating in a cable, the longer is the heat-treatment 
time that is needed to get the desired $R_{C}$ values. The fact that there is a trend of $R_{C}$ to decrease with increasing coating thickness is a clear indication that $R_{C}$ is not mainly determined by the intermetallic bulk resistivity. This is also confirmed by the resisitivity values shown in Table $\mathrm{I}$ for $\mathrm{Cl}_{3} \mathrm{Sn}$ and $\mathrm{Cu}_{6} \mathrm{Sn}_{5}$, which are both similar to the $\mathrm{Sn}-3.5 \mathrm{Ag}$ solder alloy electrical resistivity.

\section{B. Variations of the true interstrand contact area during thermal treatment}

The strands in Rutherford cables may be described as cylinders that are placed crosswise (so-called cross rod contacts). During the cabling process and in the magnet coils the strand contacts yield under the applied contact load, forming the interstrand contact areas that are seen in Fig. 2 on a macroscopic scale. As shown in the FIB images in Fig. 3 both the $\mathrm{Cu}$ strand matrix and the soft $\mathrm{Sn}-\mathrm{Ag}$ coating alloy yield plastically during the cabling process.

During the $200^{\circ} \mathrm{C}$ cable heat treatment the surface roughness is strongly increased with respect to the nonheattreated coating due to the entire transformation of the coating alloy into the hard $\mathrm{Cu}_{3} \mathrm{Sn}$ intermetallic layer. A comparison between the FIB inages acquired outside and inside the contact zone of the heat-treated strands (see Fig. 4) indicates that there is hardly any plastic deformation of the comparatively hard $\mathrm{Cu}_{3} \mathrm{Sn}$ layer under the average pressure of $50 \mathrm{MPa}$ to which the LHC cable samples were exposed prior to the FIB analysis.

Because of the surface roughening and hardening it can be expected that the true contact area is reduced during the cable heat treatment, provided that heat-treatment temperature and time are sufficient to react the entire $\mathrm{Sn}$ with $\mathrm{Cu}$. The interstrand current flow is therefore restricted at the contact surface (constriction resistance). If the heat-treatment time is too short and a soft alloy layer remains this yields plastically under the applied load, giving rise to a true contact area that can be even larger than that found on a nonheat-treated strand (see Fig. 5).

Apart from the contact topography the constriction resistance also depends on the conducting properties of the contact pair materials (metallic, semiconducting, or insulating). For the case of contacts between metallic conductors it can be shown that the contact resistance is nearly inversely proportional to the true contact area. ${ }^{24}$ When, however, a metallic conductor is entirely covered by an insulating film through which electrons can penetrate through the tunnelling effect, a reduction of the true contact area has a comparatively small influence on $R_{C}{ }^{25}$

As seen in Fig. 6 the current flow between two strands is not only restricted at the outer strand surface but also at the $\mathrm{Cu}-\mathrm{Cu}_{3} \mathrm{Sn}$ interfaces. The restriction occurs at the so-called Kirkendall voids, which are formed during the interdiffusion process in $\mathrm{Cu}-\mathrm{Sn}$ pairs. ${ }^{26}$

\section{Influence of CuSn intermetallics on the surface oxidation}

The formation of CuSn intermetallics can indirectly affect $R_{C}$ by influencing the type and thickness of the surface oxides that grow during the cable heat treatment in air.
The oxides present on pure $\mathrm{Sn}$ or $\mathrm{Sn}-3.5 \mathrm{Ag}$ oxidized in ail at ambient conditions are supposed to be a mixture between $\mathrm{SnO}$ and $\mathrm{SnO}_{2}{ }^{27}$ However, despite the fact that the formation of $\mathrm{Sn}$ oxides is thermodynamically favored over the formation of $\mathrm{Cu}$ oxides on heat-treated $\mathrm{Cu}_{3} \mathrm{Sn}$, mainly $\mathrm{Cu}$ oxides have been detected (on $\mathrm{Cu}_{6} \mathrm{Sn}_{5}$ mainly $\mathrm{Sn}$ oxides are formed). ${ }^{12}$ The surface analysis results obtained at CERN confirm the presence of $\mathrm{CuO}$ on the heat-treated strands.

A particularly rapid oxide growth in air and in an oxygenated electrolyte is reported to occur on $\mathrm{Cu}_{3} \mathrm{Sn}^{27}$ These oxides are more difficult to remove than the native oxides on the respective pure metals, which is a reason for the extreme difficulties to wet $\mathrm{Cu}_{3} \mathrm{Sn}$ by $\mathrm{Sn}$ base solders. It is assumed that the oxides formed on $\mathrm{Cl}_{3} \mathrm{Sn}$, which can be composed essentially of $\mathrm{Cu}$ oxides, mainly contribute to the contact resistance in the LHC cables.

The strand oxide films may be mechanically fractured when loaded. As seen in Fig. 7 the oxides on the irregular intermetallic layers appear to be easily fractured, giving rise to the formation of metallic bridges through the oxide. These metal-to-metal contacts are likely to cause a significant $R_{C}$ reduction as compared with the nonfractured oxide, as it is observed on the $02 \mathrm{~B}$ stiand.

The formation of a continuous $\mathrm{Cll}_{3} \mathrm{Sn}$ layer seems, therefore, to be required in order to obtain a homogeneous and sufficiently thick and stable strand oxide layer and, thus, to obtain the desired interstrand contact resistance in the LFIC cables.

\section{CONCLUSION}

The intermetallic $\mathrm{Cu}_{3} \mathrm{Sn}$ layer contributes to the contact resistance through an increased constriction resistance and through its influence on the oxides that are formed during the cable heat treatment in air. The latter appears to be the more important effect. A more detailed study about the oxidation processes of the LHC superconducting strands will be addressed in a further study.

\section{ACKNOWLEDGMENTS}

We are grateful to D. Richter for helpful advice about the LHC strand coatings and to G. Grossmann from the EMPA for fruitful discussions about CuSn intermetallics in solder joints.

IThe LHC Study Group, CERN/AC/95-0S, 1995.

${ }^{2}$ J. D. Adam et al., IEEE Trans, Appl, Supercond, 12, 1056 (2002).

${ }^{3}$ J.-M. Depond, D. Leroy, L, R. Oberli, and D. Richter, IEEE Trans. Appl. Supercond. 7, 793 (1997)

${ }^{4}$ D. Richler, J. D. Adam, D. Leroy, and L, R, Oberli, 1EEE Trans. Appl. Supercond. 9, 735 (1999)

${ }^{5}$ D. Richter, J, D. Adam, J.-M. Depond, D. Leroy, and L. R, Oberli, IEEE Trans. Appl. Supercond. 7, 786 (1997).

'A. K. Ghosh, SSC Tecluical Note No. 103, SSCL-N-808 1992.

${ }^{7}$ A. Nijhuis, H. H. J. ten Kate, V. Pantsyrny, A. K. Shikov, and M. Santini, IEEE Trans. Appl. Supercond. 10, 1051 (2000).

${ }^{8}$ M. D. Sumption, E. W. Collings, R. M. Scanlan, A. Nijhuis, H. HI. J, ten Kate, S. W. Kim, M. Wake, and T. Shintomi, Cryogenics 39, 1 (1999).

${ }^{9} B$. R. Allenby et al, Surface Mounl Int, 2, 1251 (1992).

${ }^{10}$ P. Lauro, S. K. Kang, W. K. Choi, and D. Y. Shi, J. Electron. Mater. 32, 1432 (2003).

"M. M. Scliwartz, Fundamentals of Soldering, ASM Handbook Vol. 6 (American Sociely for Metals, Metals Park, OH, 1993). 
${ }^{12}$ H. J. Reynolds and J. W. Morris, J, Electron. Mater. 24, 1429 (1995).

${ }^{13}$ W. Huang, J. M. Loman, B, Sener, Microelectron. Reliab. 42, (2002), 1229

${ }^{14}$ Alloy Phase Diagrams, ASM Handbook Vol. 3 (American Society for Metals, Metals Park, OH, 1992).

${ }^{\text {IS }}$. T. Vianco, K. L. Exickson, and P. L. Hopkins, J. Electron. Mater. 23, 721 (1994).

${ }^{16} \mathrm{~F}$. Ochoa, J. J. Willians, and N. Chawla, J. Electron. Mater. 32, 1414 (2003).

${ }^{17}$ I. E. Anderson, B. A. Cook, J. Harringa, and R. L. Terpstra, J. Electron. Mater, 31, 1166 (2002).

${ }^{18}$ K. N. Tu and R. D. Thompson, Acta Metall. 30, 947 (1982).

${ }^{19}$ N. Presser, M. R. Hilton, Thin Solid Films, 308-309, 369 (1997)

${ }^{20} \mathrm{C}$. Scheuerlein, G. Arnau Izquierdo, N. Charras, L. R. Oberli, and M. Taborelli, J. Electrochem. Soc. 151, E206 (2004).

${ }^{21} \mathrm{C}$. Scheuericin, M. Carosone, S. Ilie, D. Letant, and C. Petitjean, CERN, AT-MAS Technical note 2004-01 2004.

${ }^{22}$ Pl. Gasser, U. Xlotz, F. A. Khalid, and O. Beffort, Microse. Microanal.
10,1 (2004)

${ }^{23}$ S. Bader, W. Gust, and H. Hieber, Acta Metall, Mater. 43, 329 (1995).

${ }^{24} \mathrm{~L}$. Kogut and K. Komvopoulos, J. Appl. Phys. 94, 3153 (2003).

${ }^{25}$ L. Kogut and K. Komvopoulos, J. Appl. Phys, 95, 576 (2004).

${ }^{26} \mathrm{H}$. Oikawa and A. Hosoi, Scr. Metall, 9, 823 (1975).

${ }^{27} \mathrm{D}$. M. Tench, in The Mechanics of Solder Alloy Wetting of Spreading, edited by F, G. Yost, F, M. Hosking, and D. R. Frear (Van Nostrand Reinhold, New York, 1993).

${ }^{28} \mathrm{X}$. Deng, M. Koopman, N. Chawla, and K. K. Chawla, Mater. Sci. Eng., A 364,240 (2004).

${ }^{20}$ Handbook of Chemistry and Physics, 76 th ed., edited by D. R. Lide (CRC, Boca Ratol, FL, 1995).

${ }^{30} \mathrm{~J}$. P. Lucas, A. W. Gibson, and K. N. Subramanian, Mater. Res. Soc. Symp. Proc. 522, 3 (1998).

${ }^{31}$ R. R. Chromik, R. P. Vinci, S. L. Allen, and M. R. Notis, J. Mater, Res. $18,2251(2003)$.

${ }^{32}$ H. P. R. Frederikse, R. J. Fields, and A. Feldman, J. A.ppl. Phys. 72, 2879 (1992). 